\title{
Frequency of Distal Sensory Polyneuropathy among Diabetics in Parakou in 2012
}

\author{
Adoukonou Thierry ${ }^{1,2 *}$, Kouna-Ndouongo Philomène ${ }^{3}$, Sourokou Boni Justine'2, \\ Imorou Abdoulaye ${ }^{4}$, Houinato Dismand ${ }^{5}$ \\ ${ }^{1}$ Unité d'Enseignement et de Recherche de Neurologie, Faculté de Médecine, Université de Parakou, Parakou, \\ Benin \\ ${ }^{2}$ Unité de Neurologie du service de Médecine du Centre Hospitalier, Universitaire de Parakou, Parakou, Benin \\ ${ }^{3}$ Service de Neurologie CHU Libreville, Libreville, Gabon \\ ${ }^{4}$ Unité Diabète du Centre Hospitalier, Universitaire de Parakou, Parakou, Benin \\ ${ }^{5}$ Unité d'Enseignement et de Recherche de Neurologie, Faculté des Sciences de la Santé, Université \\ d'Abomey-Calavi, Cotonou, Benin \\ Email: ${ }^{*}$ adoukonouthierry@yahoo.fr
}

Received 17 June 2015; accepted 25 August 2015; published 28 August 2015

Copyright (C) 2015 by authors and Scientific Research Publishing Inc.

This work is licensed under the Creative Commons Attribution International License (CC BY).

http://creativecommons.org/licenses/by/4.0/

(c) (i) Open Access

\begin{abstract}
Background: The distal sensory polyneuropathy (DSP) was more frequent among diabetics, although its determinant was not well known among diabetics in Benin. Objective: We aimed to assess the frequency of DSP and its determinants among diabetics at Parakou. Methods: It was a cross-sectional study carried out from 1 March to 31 August 2012 and included 336 diabetics followed at the diabetes unit of Parakou hospital. The diagnosis of DSP was based on DNS (Diabetic Neuropathy Score) criteria and other criteria. All data concerning the diabetes mellitus were recorded. We used Epi-Info and SPSS 16.0 software to perform analysis. Results: They were 187 females $(56.0 \%)$ with the mean age of $54.9 \pm 10.9$ years. 298 patients fulfilled criteria for DSP; the overall prevalence of DSP was $\mathbf{8 8 . 7 \%}$. The main associated factors in multivariate analysis were treatment duration of diabetes more than 4 years: $\mathrm{OR}=36.7$ [4.0 -336.9$]$; the elevated glycaemia: $\mathrm{OR}=$ 3.1 [1.4 - 7.1]; the activity with high income: $\mathrm{OR}=0.2$ [0.0 - 0.8]; the ethnicity: nagots/fon: $0 \mathrm{R:} 3.7$ [1.4 - 12.5]. Conclusion: Those results suggested the high frequency of DSP among diabetics at Parakou.
\end{abstract}

\section{Keywords}

Distal Sensory Polyneuropathy, Diabetes, Neuropathy, Frequency

\footnotetext{
${ }^{*}$ Corresponding author.
} 


\section{Introduction}

Diabetic distal sensory polyneuropathy is a kind of metabolic peripheral neuropathy occurring in diabetics who have long, strong and poorly controlled hyperglycemia. This is most often polyneuropathy of the lower limbs, sensorimotor distal predominantly distal [1]. It is defined by the presence of symptoms and/or signs of nerve damage to the secondary device diabetes after exclusion of other causes of neuropathy [1] [2]. This is the most common complication of diabetes. The distal sensory polyneuropathy has been shown to consist of distal axonal degeneration dying back type and due to metabolic effect of hypoxia and microvascular disease. The main symptoms are burning feet, numbness, tingling sensation and other paresthesia and rarely motor symptoms. Its prevalence is very different depending on the study, from $8 \%$ to nearly $93 \%$ in relation to the disparity of criteria used [3]-[6]. African studies using electroneuromyography (EMG) are rare. Indeed, in a study conducted in Abidjan and using this tool the prevalence of polyneuropathy in this population was $80 \%$ [ 4 ]. Simple clinical tools provide a good accuracy and can be used to assess these polyneuropathy. They are more sensitive than electroneuromyography and seem very adapted to our context where the prohibitive cost of EMG and the unavailability of this tool are the rule. The objective of this study was to determine the frequency of distal sensory polyneuropathy in a diabetic population in northern Benin in 2012.

\section{Methods}

\subsection{Setting}

The study was conducted in the Diabetes Unit of the County Hospital in Parakou Borgou located $450 \mathrm{~km}$ north-east from Cotonou. It is the regional hospital of reference for northern Benin. The diabetes unit is established since 2010 with the World Foundation of Diabetes and monitors and the management of diabetic patients. A diabetes specialist doctor monitors and patients requiring hospitalization are treated in the hospital's medical ward where work an internist, a neurologist, a cardiologist and a nephrologist.

\subsection{Methodology}

\subsubsection{Type and Period of Study}

We conducted a cross-sectional study from 1 March to 31 August 2012.

\subsubsection{Study Population}

All diabetics followed in diabetes Unit of University hospital of Parakou.

Inclusion criteria:

It included all diabetics followed in Diabetes Unit of University hospital of Parakou.

\subsubsection{Exclusion Criteria}

Pregnant women and other bilateral amputees who could not answer questions were excluded.

\subsubsection{Sampling}

Extensive recruitment of all diabetics fulfilling the inclusion criteria and were seen in consultation during the study period. The active list at the start of data collection was 662 diabetic tracked to diabetes unit at Parakou University hospital but only about $60 \%$ of these patients were regularly monitored for a total workforce of 398 diabetics start of collection. The number of respondents was 336 diabetic patients.

\subsubsection{Data Collection}

The interview and the documentary exploitation (the records of the patients were operated) were the techniques used to collect data during the study period.

A written questionnaire was administered to every diabetic; data were supplemented with the counting of patient records.

Data collection was preceded by pretest data collection tools on some diabetic patients who were not picked up at the Diabetes Unit of University Hospital of Parakou.

\subsection{Diagnostic Criteria of Distal Sensory Polyneuropathy}

Was regarded as having a distal sensory polyneuropathy any diabetic with at least one of the following criteria: 
$\checkmark$ a score of at least 1 on the DNS (Diabetic Neuropathy Score) [7];

$\checkmark$ impaired vibration sense;

$\checkmark$ alteration of tendon reflex;

$\checkmark$ alteration in monofilament $10 \mathrm{~g}$ test.

DNS is a tool consisting of four (4) items; each item was hand 0 if absent and 1 if it is present. The four (4) items are formulated as follows:

$\checkmark$ Do you have any numbness in your feet?

$\checkmark$ Do you have a tingling sensation in your feet?

$\checkmark$ Do you have a burning or tingling sensation in your feet?

$\checkmark$ Do you have a sensation of instability worsened by darkness when you walk?

General signs of polyneuropathy were sought in the interrogation: paresthesia (tingling, tingling, heat sensation); dysesthesia (intolerance to contact sheets).

All interviewees had undergone a neurological examination involving the study of tendon reflex, the study of vibration sense in tune with $128 \mathrm{~Hz}$ and surface sensitivity and the monofilament test of $10 \mathrm{~g}$.

Diabetes mellitus: Subjects were considered diabetic if they were previously diagnosed as diabetic or when fasting glycaemia was greater than or equal to $126 \mathrm{mg} / \mathrm{dl}$.

Data on diabetes disease (type, duration of disease, treatment, complications, the last patient's blood glucose, the last glycosylated hemoglobin), vascular history, socio-demographic data (age, sex, level of education, profession, having an income generating activity...) anthropometric data (weight, height and body mass index), other potential factors purveyors of polyneuropathy were wanted in the record or for lack of it in the interrogation (taking neurotoxic drugs, possible exposure to toxic, HIV, viral hepatitis $\mathrm{C}$ ). Research complications ankle brachial index (ABI: ratio between systolic blood pressure at the ankle and the humeral) was determined routinely in all patients to search for arterial disease (defined as ABI $<0.9$ ), a strip urinary looking for proteinuria (the positive) defined nephropathy. Close examination of the feet was performed to search for lesions for diabetic foot. Postural hypotension was systematically sought in all.

\subsection{Data Collection and Statistical Analysis}

The collected data were entered, processed and analyzed using SPSS Version 16.0 software.

Qualitative variables expressed as a percentage and quantitative variables on mean with a standard deviation.

Frequency comparisons were made using the Chi-2 test (or Fisher's exact test as appropriate) and those means using the Student $\mathrm{t}$ test. To study the association between distal sensory polyneuropathy and selected variables, we performed a multivariate analysis using the logistic regression model. We introduced simultaneously in the model, all variables with $\mathrm{p}<0.05$ by performing successive iterations of step type down. In the final model, the strength and stability of the association was estimated by the prevalence ratio (PR) and its $95 \%$ confidence interval.

\subsection{Ethical Issues}

The study was approved by the Ethics Committee of the Medical Faculty of Parakou and obtained the permission of the management of the hospital. The verbal informed consent was obtained for each participant because many of them were illiterate. After giving information about the study (aim and advantage and eventual consequence for them) participants were invited to participate. If they refused it was no consequence on their care. This consent procedure was approved by the Ethics committee of the Faculty of Médecine of Parakou. Anonymity and confidentiality of data were respected.

\section{Results}

During the study period, 398 eligible patients were expected. However the number of patients in the study who had been proposed was 336. No refusal to participation was noted. For various reasons, the 62 remaining patients did not come for consultation at the time of the study and could not be approached. The enrollment rate was therefore $84.4 \%$.

Among the 336 patients 187 (55.7\%) were female. They were aged 24 to 86 years with an average age of $54.9 \pm$ 10.9 ans; they were illiterate $(57 \%)$ and had no income generating activities $(77 \%)$. Only 10 patients had type 1 
diabetes $286(85.1 \%)$ were on oral antidiabetic agents associated with the plan and $50(14.9 \%)$ were on oral antidiabetic agents associated with insulin. Family history of diabetes were noted in $164(48.8 \%)$ and $206(61.3 \%)$ patients were also hypertensive and 201 (59.8\%) were overweight or obese, while $56.3 \%$ had $\mathrm{HbA1c}>7 \%$. The prevalent complications in patients were diabetic nephropathy $(17.6 \%)$, occlusive arterial disease $(16.3 \%)$ and diabetic foot (12.8\%) while $64(19.1 \%)$ of subjects had orthostatic hypotension.

Among the 336 subjects 298 (88.7\%) met the criteria of distal sensory polyneuropathy (taking into account the composite endpoint DNS $\geq 1$ and/or abnormal sensitivity to vibrations and/or alteration of the tendons reflex and/or alteration of the monofilament test). The prevalence of distal sensory polyneuropathy was therefore $88.7 \%$. Frequencies taking into account the different criteria are summarized in Table 1.

The prevalence of distal sensory polyneuropathy (DSP) increases with age $(p=0.04)$. There is an association between the presence of distal sensory polyneuropathy and sex $(p=0.03)$, ethnicity $(p=0.04)$, having an income generating activity (IGA) $(p=0.009)$ and marital status $(p=0.03)$ of patients. But neither religion $(p=0.6)$ or level of education $(0.3)$ or marital status $(\mathrm{p}=0.05)$ were associated with the DSP. Neither alcohol nor a family history of diabetes or exposure to neurotoxic drugs was associated with the PSD. These data are summarized in Table 2. Among the complications of diabetes or the presence of PAD $(p=0.08)$, or the existence of a renal disease $(p=0.1)$ or the presence of retinopathy $(p=0.5)$ were associated with the DSP. However orthostatic hypotension was significantly more frequent in patients with DSP. The prevalence of DSP according to diabetes-related characteristics are summarized in Table 3.

In multivariate analysis the factors associated with the DSP remain ethnicity, blood glucose, the duration of treatment and the existence of an income-generating activity in patients. These data are summarized in Table 4.

Clinically the 298 subjects with distal sensory polyneuropathy had paresthesia often like pins and needles (51.3\%), numbness (34.7\%) burns (55.7\%) and cramps (39.6\%). A physical examination superficial hypoesthesia was found in 99 (33.2\%) patients and anesthesia in 19 (6.4\%). 101 (33.9\%) had pain in neuropathic character.

\section{Discussion}

The objective of this study was to investigate the importance of distal sensory polyneuropathy in the diabetic population at the Parakou University hospital. To meet this goal, a cross-sectional study is appropriate; similarly, the exhaustive sampling with a participation rate of $84.4 \%$ gives validity to our results. Furthermore, we used the diagnostic criteria which have good validity. Indeed, the DNS has a sensitivity of 79\% and a specificity of 78\% [7]. The monofilament test and vibration sensitivity are conventional tests which also have a sensitivity of $81 \%$ each and a specificity of $56 \%$ and $58 \%$ respectively [7]. The sensitivity and specificity of three combined tools have not been studied. But their combination is expected to increase or improve the sensitivity of the DNS that is already $79 \%$. In total we believe we have used a tool sensitive enough and therefore suitable for screening studies (screening). However, the specificity should be improved if they were to select patients for tests or specific pharmacological interventions. We could have previously studied the validity (sensitivity and specificity) of this combination before use. These tools, however, are not adapted for the screening of all diabetic neuropathies but only for distal sensory polyneuropathy. Indeed, in our study, we have not studied all diabetic neuropathies but only the distal sensory polyneuropathy. Diagnostic tools are adapted to this type of neuropathy in this population. Furthermore, the study population can represent all diabetics as this is usually that of patients with complicated diabetes. Another limiting factor was the unavailability of additional examinations. However we know that genuine sensory neuropathy can be electrophysiologically normal and sometimes in clinically silent

Table 1. Prevalence of distal sensory polyneuropathy according to diagnosis criteria, Parakou, 2011.

\begin{tabular}{ccc} 
Criteria & Number & Prevalence \\
\hline${ }^{*} \mathrm{DNS} \geq 1$ & 277 & 82.4 \\
Monofilament $10 \mathrm{~g}$ test & 66 & 19.6 \\
Alteration of vibration sense & 96 & 28.6 \\
\hline $\begin{array}{c}\text { DNS } \geq \mathbf{1} \text { and/or alteration vibration sense and/or alteration } \\
\text { of tendons reflex and/or monofilament 10 g test }\end{array}$ & $\mathbf{2 9 8}$ & $\mathbf{8 8 . 7}$ \\
\hline
\end{tabular}

${ }^{*}$ DNS $=$ Diabetic neuropathy score. 
Table 2. Prevalence of DSP according to socio-demographics characteristics and diabetic history, Parakou, 2011.

\begin{tabular}{|c|c|c|c|}
\hline Variables & $\begin{array}{l}\text { Population } \\
\text { N (\%) }\end{array}$ & $\begin{array}{c}\text { Distal Sensory Polyneuropathy } \\
\text { N (\%) }\end{array}$ & $\mathrm{p}$ \\
\hline $\begin{array}{c}\text { Age (years) } \\
\quad<50 \\
\geq 50\end{array}$ & $\begin{array}{l}91(27.1) \\
245(72.9)\end{array}$ & $\begin{array}{c}75(82.4) \\
223(91.0)\end{array}$ & 0.02 \\
\hline $\begin{array}{l}\text { Gender } \\
\text { Male } \\
\text { Female }\end{array}$ & $\begin{array}{l}149(44.3) \\
187(55.7)\end{array}$ & $\begin{array}{l}126(84.6) \\
172(92.0)\end{array}$ & 0.03 \\
\hline $\begin{array}{c}\text { Ethnicity } \\
\text { Fon } \\
\text { Bariba } \\
\text { Dendi } \\
\text { Nagots } \\
\text { Autres }\end{array}$ & $\begin{array}{c}56(16.7) \\
107(31.9) \\
73(21.7) \\
65(19.3) \\
35(10.4)\end{array}$ & $\begin{array}{c}45(80.4) \\
96(89.7) \\
62(84.9) \\
61(93.8) \\
34(97.1)\end{array}$ & 0.04 \\
\hline $\begin{array}{c}\text { Income generating } \\
\text { Yes } \\
\text { No }\end{array}$ & $\begin{array}{l}259(77.1) \\
77(22.9)\end{array}$ & $\begin{array}{l}224(86.5) \\
74(96.1)\end{array}$ & 0.009 \\
\hline $\begin{array}{l}\text { Tabac } \\
\text { Yes } \\
\text { No }\end{array}$ & $\begin{array}{c}8(2.4) \\
328(97.6)\end{array}$ & $\begin{array}{c}5(62.5) \\
293(89.3)\end{array}$ & 0.02 \\
\hline $\begin{array}{c}\text { History of hypert } \\
\text { Yes } \\
\text { No }\end{array}$ & $\begin{array}{l}206(61.3) \\
130(38.7)\end{array}$ & $\begin{array}{l}190(92.2) \\
108(83.1)\end{array}$ & 0.01 \\
\hline $\begin{array}{l}\text { Alcohol } \\
\text { Yes } \\
\text { No }\end{array}$ & $\begin{array}{c}25(7.4) \\
311(92.6)\end{array}$ & $\begin{array}{l}21(84.0) \\
277(89.1)\end{array}$ & 0.4 \\
\hline $\begin{array}{c}\text { Family history of } \\
\text { Yes } \\
\text { No }\end{array}$ & $\begin{array}{l}164(48.5) \\
172(51.5)\end{array}$ & $\begin{array}{l}154(93.9) \\
144(83.7)\end{array}$ & 0.6 \\
\hline $\begin{array}{c}\text { Neurotoxic drug } \\
\text { Yes } \\
\text { No }\end{array}$ & $\begin{array}{c}22(6.5) \\
314(93.5)\end{array}$ & $\begin{array}{c}21(95.4) \\
277(88.2)\end{array}$ & 0.2 \\
\hline $\begin{array}{c}\text { Matrimonial st } \\
\text { Couple } \\
\text { Alone }\end{array}$ & $\begin{array}{l}282(83.9) \\
54(16.1)\end{array}$ & $\begin{array}{c}246(87.2) \\
52(96.3)\end{array}$ & 0.05 \\
\hline
\end{tabular}

neuropathies can be observed damage to the electroneuromyography and also clinically silent histological damage. The interest of the clinical criteria is that they take into account the patient's complaint and allow appropriate management symptomatology. But these distal sensory polyneuropathies are usually axon. But a study by Adoukonou et al. [8] suggested that in the diabetic population abuses would first be demyelinating before becoming axon. These demyelinating attacks could sometimes correctly answer appropriate treatment.

The prevalence of distal sensory polyneuropathy in our study was $88.7 \%$. This figure is very high. This result is higher than Miralles-Garcia et al. [9] in 2010, who reported a prevalence of $39.6 \%$ and that of Owolabi et al. [10] in Nigeria in 2012 which had 71.1\%. Little et al. [11] in 2007 had found 10\% at diagnosis of diabetes and $50 \%, 5$ years after the diagnosis of diabetes. Vinik et al. [6] have estimated the prevalence at $93 \%$.

The disparity between our results and those reported by these studies could be due partly to the methodology used in the diagnostic tool but also to the characteristics of the populations studied. Indeed in our population the average duration of diabetes at the time of the study was about 6 years old and only 5 years in the study by Little et al. [11]. In addition, our tool is more sensitive than the tools used by different authors. For example when one considers that the monofilament test this prevalence increases to $19.6 \%$ and $82.4 \%$ if we consider only the DNS.

The high prevalence observed in our study and that of Vinik et al. [6] is explained by the fact that the diagnostic criteria used, mainly clinical, were very sensitive on the one hand and the fact that the relevant diabetic population was older and had an older diabetic disease. 
Table 3. Prevalence of DSP according to the characteristics of diabetes, Parakou, 2011.

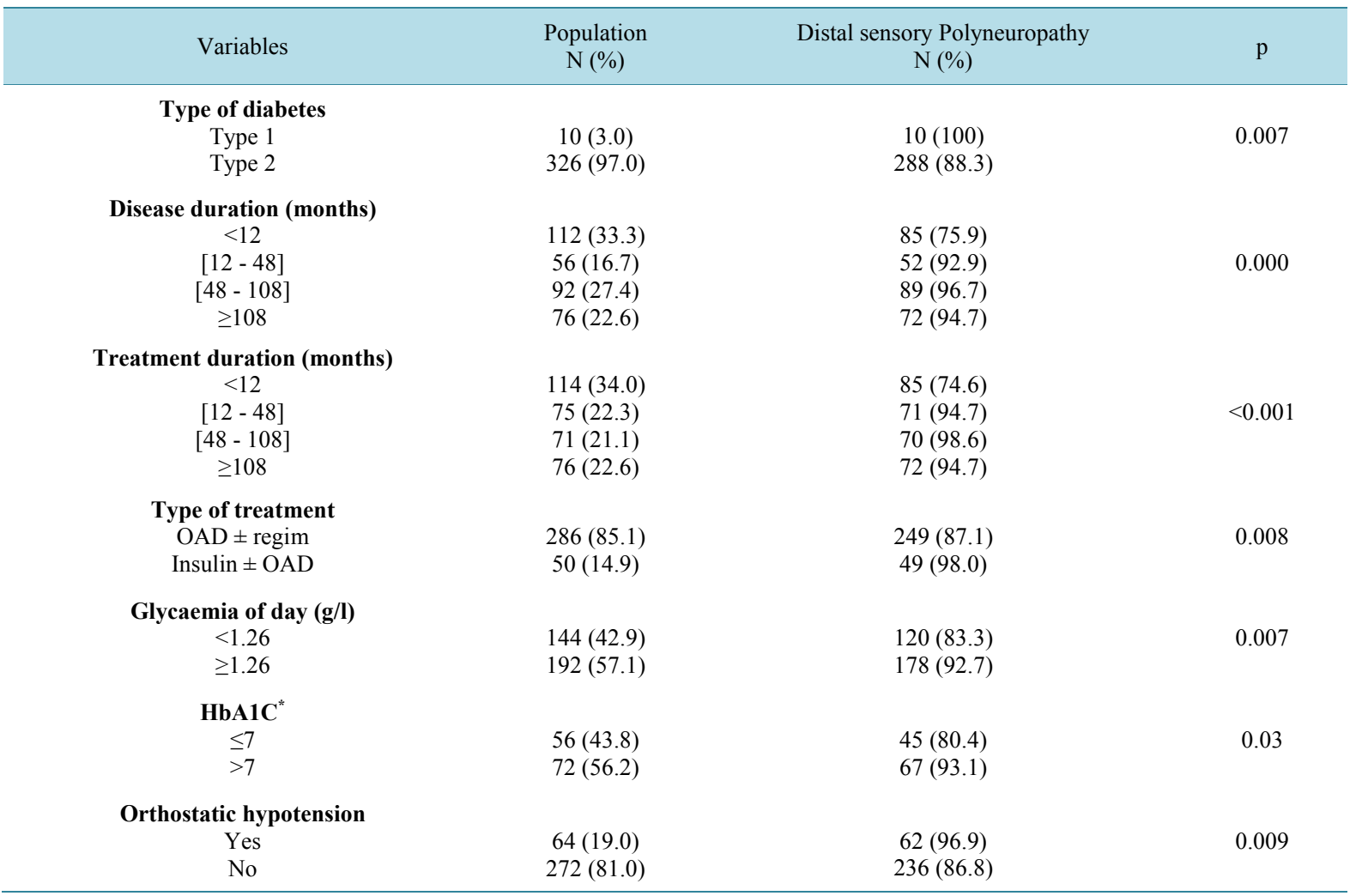

* only 128 patients had had $\mathrm{HbA1C}$ because of its cost.

Age was associated with PSD in our study. The average age of patients who had a distal sensory polyneuropathy was 55.6 years \pm 10.9 years. Oyibo et al. [12] in 2002 found $52 \pm 11.1$ years and Nguewa et al. [13] in 2011 found $56 \pm 9$ years. This similarity of results could be explained by the fact that the axonal physiological aging would create a susceptibility to hyperglycemia or that the axons of patients under 50 years have protective factors against the deleterious effects of chronic hyperglycemia. Furthermore, the chronic complications of diabetes are more common with age and could also explain the frequency of neuropathy [14].

Hyperglycemia has been reported as a risk factor associated with the occurrence of polyneuropathy in multivariate analysis. Bouya et al. [15] in 2005 in a case-control study of 110 diabetics had noted that advanced age, poor control of diabetes so permanent hyperglycemia, duration of diabetes, tobacco use, diabetes type were significantly associated with diabetic neuropathy. The same was done by Tesfaye et al. [16] in 1996.

Another study on diabetes in Bahrain in 1477 by Al-Mahroos et al. [17] in 2007 was a significant association between advanced age, poor control of diabetes, the long duration of diabetes, smoking and diabetic neuropathy. Borut et al. [18] in 2006 reported similar results.

The duration of diabetes than 10 years, the upper blood glucose $2 \mathrm{~g} / \mathrm{l}$ were the main factors found by Tabatabaei-Malazy et al. [19] in 2008. The fact that these studies have recognized hyperglycemia as a factor associated with the occurrence of polyneuropathy could be explained by: Hyperglycemia causes a disturbance of microcirculation causing a rise in blood pressure within the vessel a thrombogenic tendency, increased blood viscosity with aggregability. This results in a narrowing of the lumen of the vasa nervorum, rigidity of their wall then occurs occlusion capillary lumen and therefore apoptosis by edema, ischemia and hypoxia where neuropathies.

The fact that the lack of income-generating activity is associated with the occurrence of distal sensory polyneuropathy could be justified by the lack of financial means necessary to access the correct management of diabetes (purchase of medicines, blood sugar control, access to additional examinations and even consulting fees). These patients only come for consultation at the complication phase of neuropathies.

The Nagot ethnic group was found to be associated with the occurrence of distal sensory polyneuropathy 
Table 4. Main associated factors to DSP among diabetics, multivariate analysis using logistic regression, Parakou, 2011.

\begin{tabular}{|c|c|c|}
\hline Variables & PR [IC95\%] & $\mathbf{p}$ \\
\hline $\begin{array}{c}\text { Activity with high income } \\
\text { Yes } \\
\text { No }\end{array}$ & $\begin{array}{c}1 \\
5.0[1.3-86.8]\end{array}$ & 0.02 \\
\hline $\begin{array}{l}\text { Ethnicity } \\
\text { Fon } \\
\text { Bariba } \\
\text { Dendi } \\
\text { Nagots } \\
\text { Others }\end{array}$ & $\begin{array}{c}1 \\
2.1[0.9-5.3] \\
1.4[0.6-3.5] \\
3.7[1.1-12.5] \\
8.3[1.0-67.5]\end{array}$ & 0.04 \\
\hline $\begin{array}{c}\text { Treatment duration (months) } \\
<12 \\
{[12-48]} \\
{[48-108]} \\
\geq 108\end{array}$ & $\begin{array}{c}1 \\
3.9[1.3-11.6] \\
36.7[4.0-336.9] \\
6.1[2.0-19.3]\end{array}$ & $<0.001$ \\
\hline $\begin{array}{c}\text { Glycaemia of day }(\mathbf{g} / \mathbf{l}) \\
<1.26 \\
\geq 1.26\end{array}$ & $\begin{array}{c}1 \\
3.1[1.4-7.1]\end{array}$ & 0.007 \\
\hline
\end{tabular}

compared to his ethnicity. The power of the study could explain that; but other socio-cultural factors could explain it such as the lifestyle, the diet habit.

Our study found that over the period of treatment, the longer polyneuropathy occurred without dose effect. Indeed, patients had a duration of more than 108 months of treatment were less developed than those with polyneuropathy duration was between 48 months and 108 months. This can be explained in part by a threshold effect, but on the other by a sizeable loss of feeling suddenly decreasing the expression of sensory symptoms.

\section{Conclusion}

Distal sensory polyneuropathy is very common in our study and in part explained by the precarious economic conditions hampering the proper management of diabetes. It is therefore important to help diabetics by the socio-economic equity and patient organization for better monitoring of the disease.

\section{References}

[1] Tesfaye, S. and Selvarajah, D. (2012) Advances in the Epidemiology, Pathogenesis and Management of Diabetic Peripheral Neuropathy. Diabetes/Metabolism Research and Reviews, 28, 8-14. http://dx.doi.org/10.1002/dmrr.2239

[2] Valensi, P., Gautier, J.F., Amarenco, G., Sauvanet, J.P., Leutenegger, M. and Attali, J.R. (1997) Neuropathie autonome chez le diabétique. Diabetes Metab, 23, 89-99.

[3] Leutenegger, M., Malgrange, D., Boccalon, H., Fontaine, P., Got, I., Valensi, P., et al. (1995) Le pied diabétique. Diabetes Metab, 21, 452-457.

[4] Cowplli-Bony, P., Douayoua-Sonan, T., Adoueni, V., Adou-Lath, C. and Beugré-Kouassi, B. (2008) Le diagnostic clinique de la polyneuropathie diabétique. Méd Afr Noire, 5501, 41-45.

[5] Nsabiyumva, F., Ndikubagenzi, J., Baransaka, E. and Harindavyi, H. (2011) Aspects épidémiologiques et cliniques de 3620 diabétiques suivis au centre de Lutte contre le diabète au Burunsi. Etude rétrospective sur six ans. Méd Afr Noire, 5807, 345-349.

[6] Vinik, A.I., Holland, M.T., Le Beau, J.M., Liuzzi, F.J., Stansberry, K.B. and Cohen, L.B. (1992) Diabetic Neuropathies. Diabetes Care, 12, 1926-1975. http://dx.doi.org/10.2337/diacare.15.12.1926

[7] Meijer, J.W.G., Smit, A.J., Sonderent, E.V., Groothoff, J.W., Eisma, W.H. and Links, T.P. (2002) Symptom Scoring Systems to Diagnose Distal Polyneuropathy in Diabetes: The Diabetic Neuropathy Symptom Score. Diabetic Medicine, 19, 962-965. http://dx.doi.org/10.1046/j.1464-5491.2002.00819.x

[8] Adoukonou, T., Magy, L., Gnonlonfoun, D., Gallouedec, G., Khalil, M. and Vallat, J.M. (2008) Profil électroneurophysiologique des neuropathies dans une population de patients diabétiques admis dans un laboratoire de neurophysiologie. African Journal of Neurological Sciences, 2, 77-85.

[9] Miralles-Garcia, J.M., de Pablos-Velasco, P., Cabrerizo, L., Pérez, M. and Lopez-Gomez, V. (2010) Prevalence of 
Distal Diabetic Polyneuropathy Using Quantitative Sensory Methods in a Population with Diabetes of More than 10 Years Disease Duration. Endocrinología y Nutrición, 57, 414-420. http://dx.doi.org/10.1016/j.endonu.2010.05.006

[10] Owolabi, M.O. and Ipadeola, A. (2012) Total Vascular Risk as a Strong Correlate of Severity of Diabetic Peripheral Neuropathy in Nigerian Africans. Ethnicity \& Disease, 22, 106-112.

[11] Little, A.A., Edwards, J.L. and Feldman, E.L. (2007) Diabetic Neuropathies. Practical Neurology, 7, 82-92.

[12] Oyibo, S.O., Prasad, Y.D.M., Jackson, N.J., Jude, E.B. and Boulton, A.J.M. (2002) The Relationship between Blood Glucose Excursions and Painful Diabetic Peripheral Neuropathy: A Pilot Study. Diabetic Medecine, 19, 870-877. http://dx.doi.org/10.1046/j.1464-5491.2002.00801.x

[13] Nguewa, J.L., Sobngwi, E., Wawo, E., Azabji-Kenfack, M., Dehayem, M., Ngassam, E. and Mbanya, J.C. (2011) Neuropathie autonome cardiaque: Caractéristiques et facteurs associés dans un groupe de patients diabétiques de type 2 . Diabetes \& Metabolism, 37, A36-A108. http://dx.doi.org/10.1016/S1262-3636(11)70660-7

[14] Djrolo, F. (2009) Facteurs associés aux complications chroniques chez les diabétiques de type 2 à Cotonou. Diabetes \& Metabolism, 35, A55. http://dx.doi.org/10.1016/S1262-3636(09)71913-5

[15] Bouya, F., Bandarian, F., Larijani, B., Pajouhi, M., Noraei, M. and Lotfi, J. (2005) Potential Risk Factors for Diabetic Neuropathy: A Case-Control Study. BMC Neurology, 5, 24. http://dx.doi.org/10.1186/1471-2377-5-24

[16] Tesfaye, S., Stevens, L.K., Stephenson, J.M., Fuller, J.H., Plater, M., Ionescu-Tirgoviste, C., et al. (1996) Prevalence of Diabetic Peripheral Neuropathy and Its Relation to Glycemic Control and Potential Risk Factors: The EURODIAB IDDM Complications Study. Diabetologia, 39, 1377-1384. http://dx.doi.org/10.1007/s001250050586

[17] Al-Mahroos, F. and Al-Roomi, K. (2007) Diabetic Neuropathy Foot Ulceration, Peripheral Vascular Disease and Potential Risk Factors among Patients with Diabetes in Bahrain: A Nationwide Primary Care Diabetes Clinic-Based Study. Annals of Saudi Medicine, 27, 25-31. http://dx.doi.org/10.4103/0256-4947.51536

[18] Borut, U., Alp, R., Sargn, H., Kocer, A., Luleci, A., Sargn, P., et al. (2006) Prevalence of Peripheral Neuropathy in Type 2 Diabetic Patients Attending a Diabetes Center in Turkey. www.Cababstractsplus.org

[19] Tabatabaei-Malazy, O., Mohajeri-Tehrani, M.R., Madani, S.P., Heshmat, R. and Larijani, B. (2011) The Prevalence of Diabetic Peripheral Neuropathy and Related Factors. Iranian Journal of Public Health, 40, 55-62. 